\title{
Response to Dr. Steffen U. Eisenhardt, M.D., et al. letter to the editor
}

\author{
Bernardo Hontanilla
}

Received: 14 January 2011 / Accepted: 15 January 2011 / Published online: 8 February 2011

(C) Springer-Verlag 2011

Sir,

We thank Dr. Eisenhardt et al. for the comments suggesting that "the masseter nerve as a donor nerve can obtain spontaneous function independent of chewing motions 6 to 9 months after the first signs of reinnervation due to the quite remarkable capacity of cerebral adaptation even in adult patients". However, Dr. Eisenhardt and co-authors must distinguish between spontaneous smile and smiling without biting, which are two situations completely different from each other. Spontaneous smile is the social and unconscious smile, whereas smiling without biting is a voluntary procedure not related with spontaneity. I agree with other authors that smiling without biting is possible, especially in women, not in men, as is suggested, but not demonstrated, by Manktelow et al. [1]. However, there are many publications in the literature (especially Dr. Terzis'), including ours, indicating that spontaneous smile cannot be achieved when using the masseter nerve as a donor nerve [2]. Moreover, Dr. Labbé et al. have introduced a cross-facial nerve graft to achieve spontaneous smile in his modification of the McLaughling technique [3]. Thus, we think that the facial nerve, although not a strong nerve to obtain facial movement, is the necessary nerve to obtain a spontaneous smile. Thus, the facial nerve combined with the masseter nerve should be a better option than using the hypoglossal nerve to obtain strong and spontaneous facial motion.

\section{References}

1. Manktelow RT, Tomat LR, Zuker RM et al (2006) Smile reconstruction in adults with free muscle transfer innervated by the masseter motor nerve: effectiveness and cerebral adaptation. Plast Reconstr Surg 118:885-899

2. Terzis JK, Tzafetta K (2009) The "babysitter" procedure: minihypoglossal to facial nerve transfer and cross-facial nerve grafting. Plast Reconstr Surg 123:865-876

3. Labbé D, Hamel M, Bénateau H (2003) Lengthening temporalis myoplasty and transfacial nerve graft (VII-V). Ann Chir Plast Esthét 48(1):31-35

B. Hontanilla $(\bowtie)$

Clinica Universidad de Navarra,

Pamplona, Spain

e-mail: bhontanill@unav.es 